\begin{tabular}{|c|c|c|}
\hline $\begin{array}{l}\text { PKS } \\
\text { PUBLIC } \\
\text { KNOLLEDGE } \\
\text { PROJECT }\end{array}$ & $\begin{array}{l}\text { REVISTA DE GEOGRAFIA } \\
\text { (RECIFE) } \\
\text { http://www.revistaufpe.br/revistageografia }\end{array}$ & $\begin{array}{l}\text { OJS } \\
\text { OPEN } \\
\text { JOUNAL } \\
\text { SYSTEMS }\end{array}$ \\
\hline
\end{tabular}

\title{
ANÁLISE MORFOESTRUTURAL DA BACIA HIDROGRÁFICA DO RIBEIRÃO DA MATA NO CONTATO EMBASAMENTO ARQUEANO E BACIA SEDIMENTAR NEOPROTEROZOICA, MINAS GERAIS
}

\author{
Renata Jordan Henriques ${ }^{1}$; Roberto Célio Valadão ${ }^{2}$ \\ ${ }^{1}$ Instituto de Geociências - Universidade Federal de Minas Gerais. E-mail: renatajhques@gmail.com \\ ${ }^{2}$ Instituto de Geociências - Universidade Federal de Minas Gerais. E-mail: valadao@ufmg.br
}

Artigo recebido em 20/10/2017 e aceito em 09/03/2018

\begin{abstract}
RESUMO
As formas de relevo são comumente condicionadas por seu arcabouço geológico, a exemplo de zonas de contato geotectônico que podem revelar aspectos tanto morfoestruturais quanto morfotectônicos. É nesse contexto que se insere este trabalho cujo objetivo é investigar as influências do arcabouço geológico na evolução geomorfológica regional da bacia hidrográfica do ribeirão da Mata, uma bacia tributária do rio das Velhas localizada no vetor norte da região metropolitana de Belo Horizonte, em Minas Gerais. Essa bacia está situada na transição entre as rochas arqueanas do Complexo Belo Horizonte e as rochas sedimentares neoproterozoicas do Grupo Bambuí. Para isso foram analisadas a orientação de talvegues e interflúvios, a rugosidade superficial e a densidade da rede hidrográfica. Os resultados revelaram forte condicionante morfoestrutural possivelmente associado a mobilidades crustais capazes de alterar o nível de base regional e influenciar a dissecação da superfície pela rede hidrográfica.
\end{abstract}

Palavras-chave: Geomorfologia Estrutural; Morfoestrutura; Morfotectônica.

\section{MORPHOSTRUCTURAL ANALYSIS OF RIBEIRÃO DA MATA DRAINAGE BASIN IN CONTACT ARCHEAN CRYSTALINE BASEMENT AND NEOPROTEROZOIC SEDIMENTARY BASIN, MINAS GERAIS}

\begin{abstract}
The landforms are commonly conditioned by their geological framework, such as geotectonic contact zones that may reveal both morphostructural and morphotectonic aspects. This paper investigates the influences of the geological framework on the regional geomorphological evolution of the catchment area of the Ribeirão da Mata, an affluent basin of the Velhas river located in the northern vector of the metropolitan region of Belo Horizonte, Minas Gerais. This basin is located in the transition between the archaean rocks of the Complex Belo Horizonte and the neoproterozoic sedimentary rocks of the Bambuí Group. The orientation of talvegues and interfluves, the surface roughness and the density of the stream network were analyzed. The results revealed a strong morphostructural control possibly associated to crustal movements capable of changing the base level and influencing surface dissection by the stream network.
\end{abstract}

Key-words: Structural Geomorphology; Morphostructure; Morphotectonic. 


\section{INTRODUÇÃO}

O estado de Minas Gerais é geologicamente composto por um mosaico de unidades geotectônicas edificadas por variada tipologia de rochas ígneas, sedimentares e metamórficas, sendo a organização morfoestrutural regional de seu relevo um reflexo dessa variabilidade litoestrutural. Em Minas Gerais, a bacia sedimentar neoproterozoica do São Francisco, parte integrante do cráton do São Francisco, possui organização regional de suas formas e unidades de relevo arquitetadas diferentemente daquelas modeladas nas rochas metamórficas das faixas móveis pré-cambrianas extra cratônicas adjacentes, a exemplo do Espinhaço Meridional e de parte do Quadrilátero Ferrífero (FUNDAÇÃO CENTRO TECNOLÓGICO DE MINAS GERAIS, 1982; HASUI, 2012). Na bacia sedimentar do São Francisco as formas de relevo se expressam em extensos platôs relativamente subhorizontalizados recortados por amplos vales, cuja morfogênese está condicionada ao nível de base do rio São Francisco e de sua rede de afluentes (KING, 1956; VALADÃO, 1998, 2009).

É nesse contexto que este trabalho é conduzido pela seguinte indagação: De que modo a organização geomorfológica regional da área investigada se comporta frente ao contato geológico entre distintas unidades geotectônicas? Para isso foi selecionada uma bacia hidrográfica localizada na transição entre o escudo cristalino arqueano exumado do Complexo Belo Horizonte e a bacia sedimentar neoproterozoica do Grupo Bambuí. Essa bacia hidrográfica está localizada no vetor norte da Região Metropolitana de Belo Horizonte $(\mathrm{RMBH})$, sendo drenada pelo ribeirão da Mata, um afluente do rio das Velhas que deságua no rio São Francisco.

A bacia do ribeirão da Mata está edificada sobre dois distintos arcabouços litoestruturais: o Complexo Belo Horizonte e as sequências sedimentares das formações Sete Lagoas e Serra de Santa Helena pertencentes ao Grupo Bambuí. O Complexo Belo Horizonte constitui uma unidade arqueana bastante fraturada e composta por rochas gnáissico-graníticas datadas de 3,0-2,9Ga, cujas assinaturas geoquímicas se assemelham a suítes tonalitotrondhjemito-granodiorito, TTG (NOCE et al., 1997). Nesse complexo ocorrem, por vezes, corpos intrusivos de natureza félsica neoarqueanos $(2,7 \mathrm{Ga})$ intrudidos posteriormente à migmatização do Gnaisse Belo Horizonte (ca. 2.860 Ma) (NOCE et al., 1997). As sequências sedimentares neoproterozoicas estratigraficamente associadas ao Grupo Bambuí viabilizaram 
a formação do sistema cárstico de Lagoa Santa que, na área da bacia investigada, posiciona-se na margem esquerda do ribeirão da Mata.

A formação Sete Lagoas é dividida em dois membros, sendo o Pedro Leopoldo de composição cálcio-filítica e o Lagoa Santa composto por calcários de pureza superior a 90\% de CaCO3 (PILÓ, 1998; PESSOA, 2005). Já a formação Serra de Santa Helena é integrada sobretudo por metapelitos finos (PESSOA, 2005). Esse contato geológico entre diferentes províncias geotectônicas, segundo Magalhães Jr. e Saadi (1994), resulta em zonas de maior sensibilidade frente a campos de tensões crustais relacionadas à deriva W-NW da placa SulAmericana. Ao que tudo indica, ainda que o interior dessa placa esteja em condições de relativa estabilidade, as descontinuidades crustais existentes nessas zonas de contato favorecem a liberação de energia de tensões regionais e, por conseguinte, a reorganização geomorfológica da superfície.

O objetivo deste trabalhado é efetivar uma primeira aproximação acerca da organização morfoestrutural da bacia hidrográfica do ribeirão da Mata, buscando reconhecer como suas formas de relevo podem ter sido condicionadas regionalmente pelo arcabouço geológico e se há indícios morfotectônicos. Para isso foram adotados procedimentos voltados para a análise da organização topográfica regional da bacia investigada, notadamente a partir do processamento digital de dados altimétricos, de rugosidade e de densidade da rede hidrográfica.

\section{MATERIAL E MÉTODOS}

Para a realização da análise morfoestrutural da área de estudo foram executados os seguintes procedimentos: (i) mapeamento da bacia hidrográfica do ribeirão da Mata e de seus principais afluentes; (ii) mapeamento de lineamentos de talvegues e interflúvios identificados na superfície, baseado em Filho e Fonseca (2009), e a representação de orientação geral por diagramas de roseta; (iii) aplicação do Índice de Concentração de Rugosidade, adaptado de Sampaio e Augustin (2014); (iv) análise da distribuição superficial da rede hidrográfica; e (v) confecção de seção topográfica regional.

O primeiro procedimento foi realizado manualmente no ArcGIS 10.1 mediante curvas de nível e hidrografia, em escala 1:50.000, do projeto Geominas (IBGE, 2008). Este procedimento resultou em modelo digital de elevação ASTER, de resolução 30x30m, como 
auxílio à definição de linhas de interflúvio e talvegue. Na definição das subbacias do ribeirão da Mata foram considerados os afluentes que possuem hierarquia fluvial superior a $4^{\mathrm{a}}$ ordem segundo metodologia de Strahler (1957).

A área da bacia foi calculada a partir da ferramenta calculate geometry, disponível na tabela de atributos do ArcGIS 10.1. O segundo procedimento foi executado segundo proposta de Filho e Fonseca (2009), o qual emprega o modelo digital de elevação ASTER (resolução 30x30m) na extração de sombreamento do relevo nos azimutes 45, 315 e 359, com ângulo de elevação solar de $35^{\circ}$, graças ao emprego da ferramenta Hillshade do ArcGIS 10.1. A partir do reconhecimento de diferentes perspectivas de sombreamento, foram mapeados manualmente os lineamentos que acompanham linhas de talvegue e de interflúvio.

$\mathrm{Na}$ análise da orientação desses lineamentos foi empregado o azimuthfinder como proposto por Queiroz et al. (2014) em relação ao toolbox do ArcGIS, que possibilita a extração de uma tabela .txt formatada sobre os azimutes de cada lineamento. Essa tabela, por sua vez, foi processada no programa Stereonet 7 e seus resultados representados em diagramas de roseta quanto a frequência acumulada dos lineamentos.

O Índice de Concentração de Rugosidade - ICR foi empregado a partir de adaptação da proposta de Sampaio e Augustin (2014), com vistas a efetivar classificação morfométrica segundo distribuição espacial da declividade das vertentes por meio do estimador de densidade de Kernel. Para tanto, foram extraídos os graus de declividade a partir do ASTER pela ferramenta slope do ArcGIS 10.1, distinguindo-se cinco classes de declividade de acordo com os aspectos morfológicos da superfície que compreendem os intervalos $0-5^{\circ}, 5-12^{\circ}, 12-$ $20^{\circ}, 20-30^{\circ}, 30-57^{\circ}$. Mediante emprego da ferramenta reclassify cada intervalo foi convertido a classes entre 1 a 5, sendo a primeira referente ao primeiro intervalo. Esse dado matricial de classes foi convertido em um dado vetorial de pontos pelo raster to point, sendo seu resultado aplicado ao Kernel Density por varredura de $1.000 \mathrm{~km}^{2}$.

Para a densidade da rede hidrográfica foi também utilizada a ferramenta Kernel Density em varredura de $1.000 \mathrm{~km}^{2}$ a partir da base linear de hidrografia do projeto Geominas (IBGE, 2008), em escala 1:50.000. Para a confecção da seção topográfica regional foram organizadas as classes hipsométricas a partir do ASTER, sendo utilizada a linha de interpolação (interpolate line) da ferramenta 3D Analyst do ArcGIS 10.1 na elaboração do traçado desejado, bem como utilizado o profile graph para geração da fisiografia topográfica. 


\section{RESULTADOS E DISCUSSÕES}

A bacia hidrográfica do ribeirão da Mata drena área de $817,4 \mathrm{~km}^{2}$, sendo seus principais tributários o ribeirão do Urubu $\left(138,9 \mathrm{~km}^{2}\right)$, o ribeirão das Neves $\left(176,5 \mathrm{~km}^{2}\right)$ e o ribeirão das Areias $\left(114,3 \mathrm{~km}^{2}\right)$. Há, ainda, cinco principais subbacias de canais de hierarquias fluviais superiores a $4^{\mathrm{a}}$ ordem, sendo correspondente aos córregos Sujo (50,3km²), Palmeira $\left(31,3 \mathrm{~km}^{2}\right)$, Boa Vista $\left(25,7 \mathrm{~km}^{2}\right)$, Carrancas $\left(17,6 \mathrm{~km}^{2}\right)$ e Braúna $\left(17,2 \mathrm{~km}^{2}\right)$. A bacia também revela forte assimetria entre as margens do ribeirão da Mata, sendo sua margem direita consideravelmente maior em relação à margem esquerda. A seção topográfica regional revela que a superfície modelada sobre o embasamento cristalino se encontra em cotas altimétricas mais elevadas, as quais chegam a 980m, sendo significativamente dissecadas até a cota de 750 principalmente, compreendendo os ribeirões das Neves e das Areias (Figura 1).

Figura 1 - Bacia do ribeirão da Mata: localização e organização topográfica regional
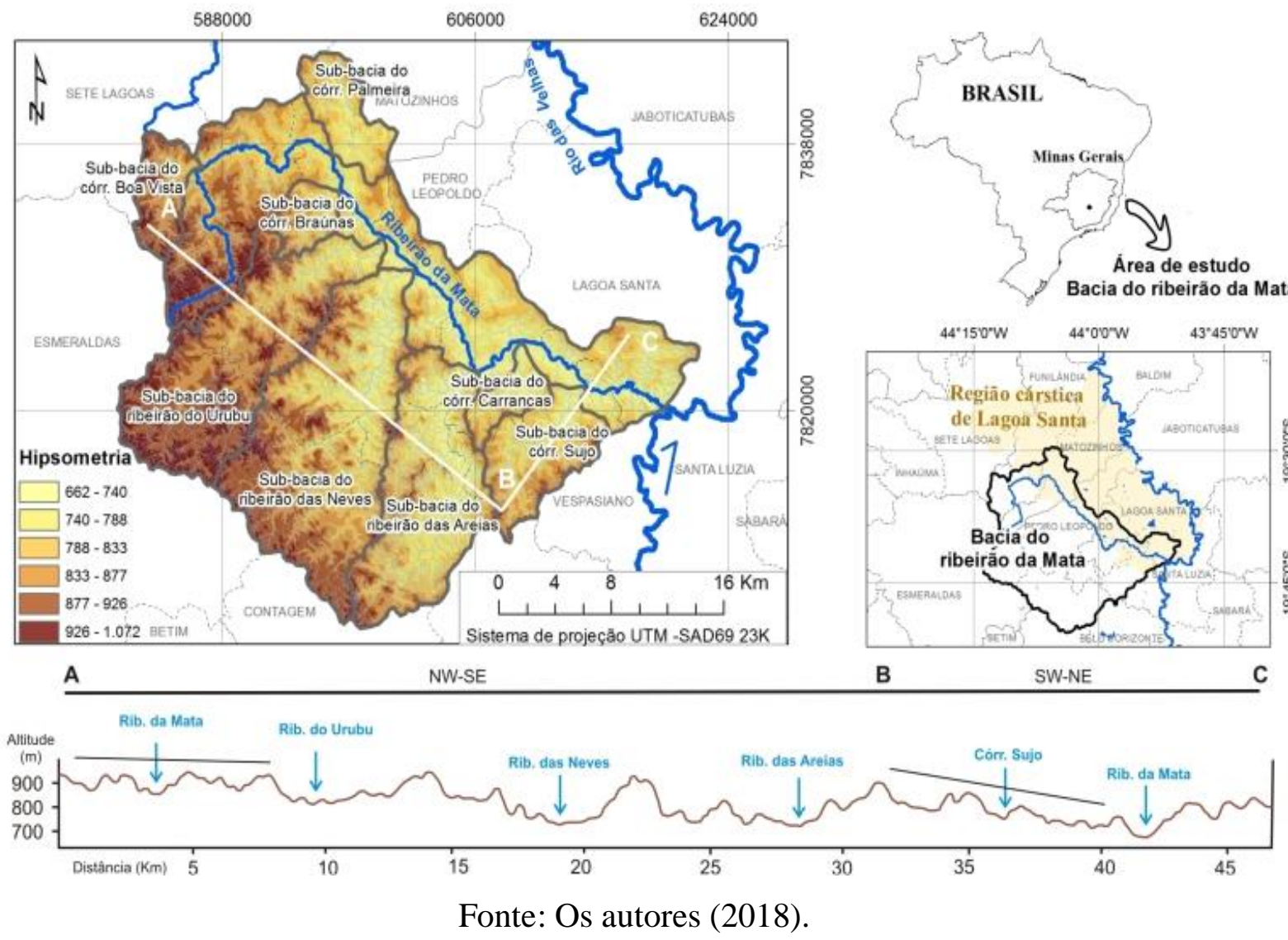
O ribeirão da Mata ocupa posição relativamente coincidente à direção NW- SE que define $o$ contato entre $\mathrm{o}$ embasamento arqueano $\mathrm{e}$ as sequências sedimentares neoproterozoicas, sendo que nestas últimas a topografia geral atinge cotas por volta de $850 \mathrm{~m}$ e vales com menor amplitude de dissecação em relação àqueles localizados no embasamento exumado. $\mathrm{O}$ vale do ribeirão da Mata, nas proximidades de sua confluência com o rio das Velhas, encontra-se em cota de $670 \mathrm{~m}$, enquanto nas cabeceiras deste ribeirão se verifica inflexão de quase $90^{\circ}$ posicionada em altitude aproximada de $880 \mathrm{~m}$. A seção topográfica indica caimento geral para NE percebido pelo trecho B-C, enquanto em A-B se revela relativa regularidade topográfica na zona de cabeceiras do ribeirão da Mata, ao passo que nesse trecho em direção jusante a morfologia se torna consideravelmente dissecada, possivelmente pelos ribeirões Urubu, das Neves e Areias. Essa organização topográfica regional sugere que a rede hidrográfica foi organizada sobre superfície modelada em rochas gnáissico-graníticas cuja alteração regional de seu nível de base, provavelmente associado ao ribeirão da Mata, favoreceu a dissecação de maneira incisiva de sua rede de afluentes que resultou na atual amplitude altimétrica observada.

A margem esquerda do ribeirão da Mata, por sua vez, encontra-se sobre arcabouço geológico que favorece processos relacionados à dinâmica cárstica, tanto recente quanto pretérita. Nesse contexto, mediante a hipótese de uma alteração geral do nível de base, a margem direita drenada sobre o complexo cristalino pode ter favorecido uma transformação superficial, ao passo que esses reflexos para a margem esquerda em relação às sequências carbonáticas podem ter seus testemunhos, sobretudo, em subsuperfície. Um aspecto notável sobre a organização superficial da bacia investigada, para além da significativa assimetria entre as margens esquerda e direita do ribeirão da Mata, se refere à orientação NW-SE desse ribeirão, ao passo que seus principais afluentes drenam perpendicularmente em orientação SW-NE.

A análise dos lineamentos identificados na superfície indica que a bacia do ribeirão da Mata possui orientação geral essencialmente NW-SE, equivalente ao sentido de drenagem do ribeirão principal (Figuras 2 e Figura 3). 
Figura 2 - Bacia do ribeirão da Mata: arcabouço geológico e orientação geral dos principais talvegues e interflúvios

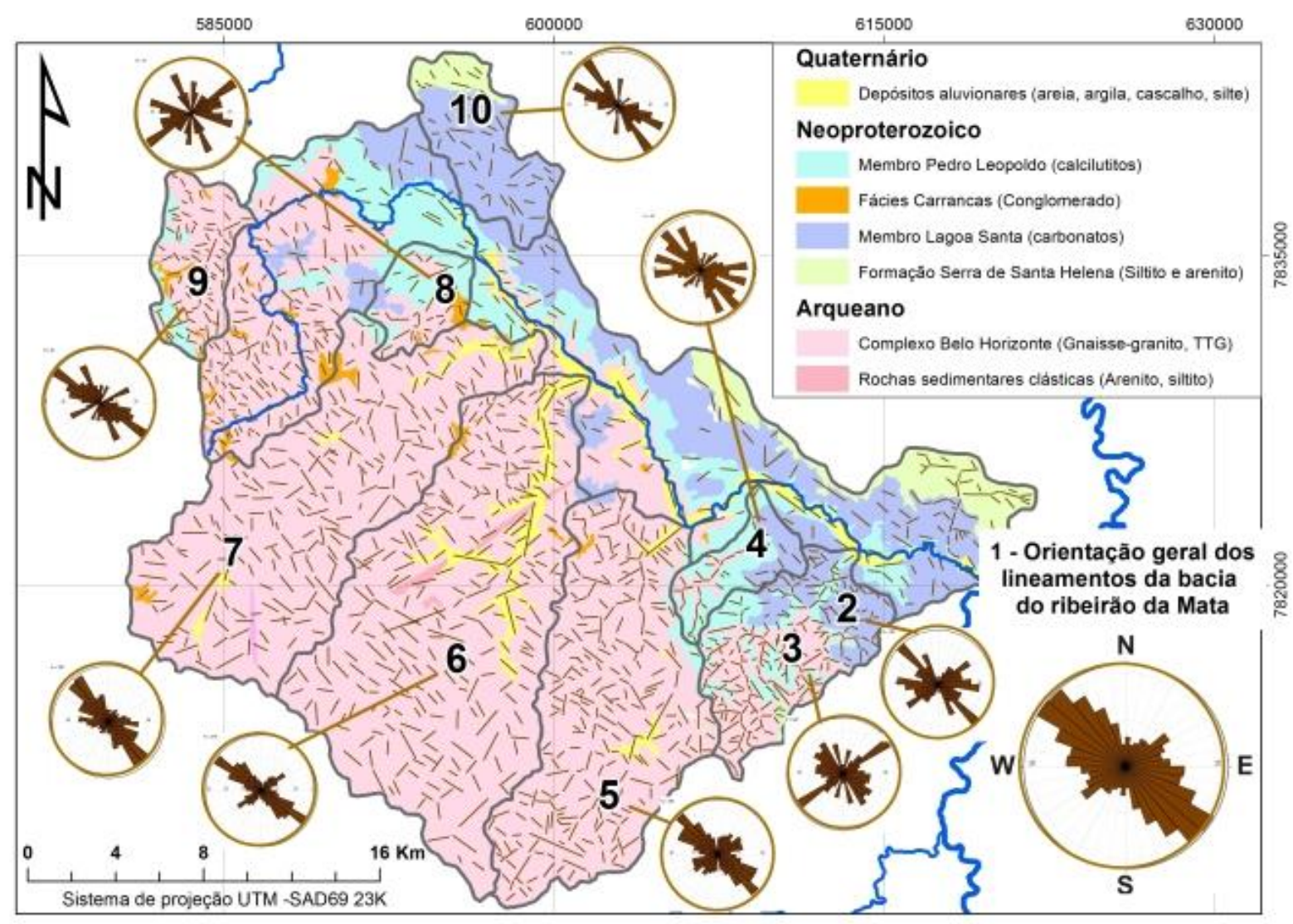

Fonte: Os autores (2018).

Secundariamente ocorre orientação SW-NE equivalente à maioria de seus principais afluentes. Essa orientação assume prevalência nas subbacias dos córregos Sujo e Braúnas, na qual ambas possuem em comum representarem exatamente o contato entre as rochas sedimentares e o complexo cristalino, diferentemente das demais que se situam sobre o embasamento exumado ou sobre as sequencias carbonáticas. É possível sugerir uma hipótese geral sobre a razão da rede hidrográfica se alinhar perpendicularmente em relação a esse contato geológico, uma vez que a organização litoestrutural possui descontinuidades predominantes NW-SE, sendo que a rede hidrográfica mediante alteração em sua capacidade de dissecação pode ter utilizado descontinuidades secundárias SW-NE que favoreceram o corte perpendicular às descontinuidades principais. 
Figura 3 - Diagramas de roseta de acumulação de frequência de orientações de talvegues e

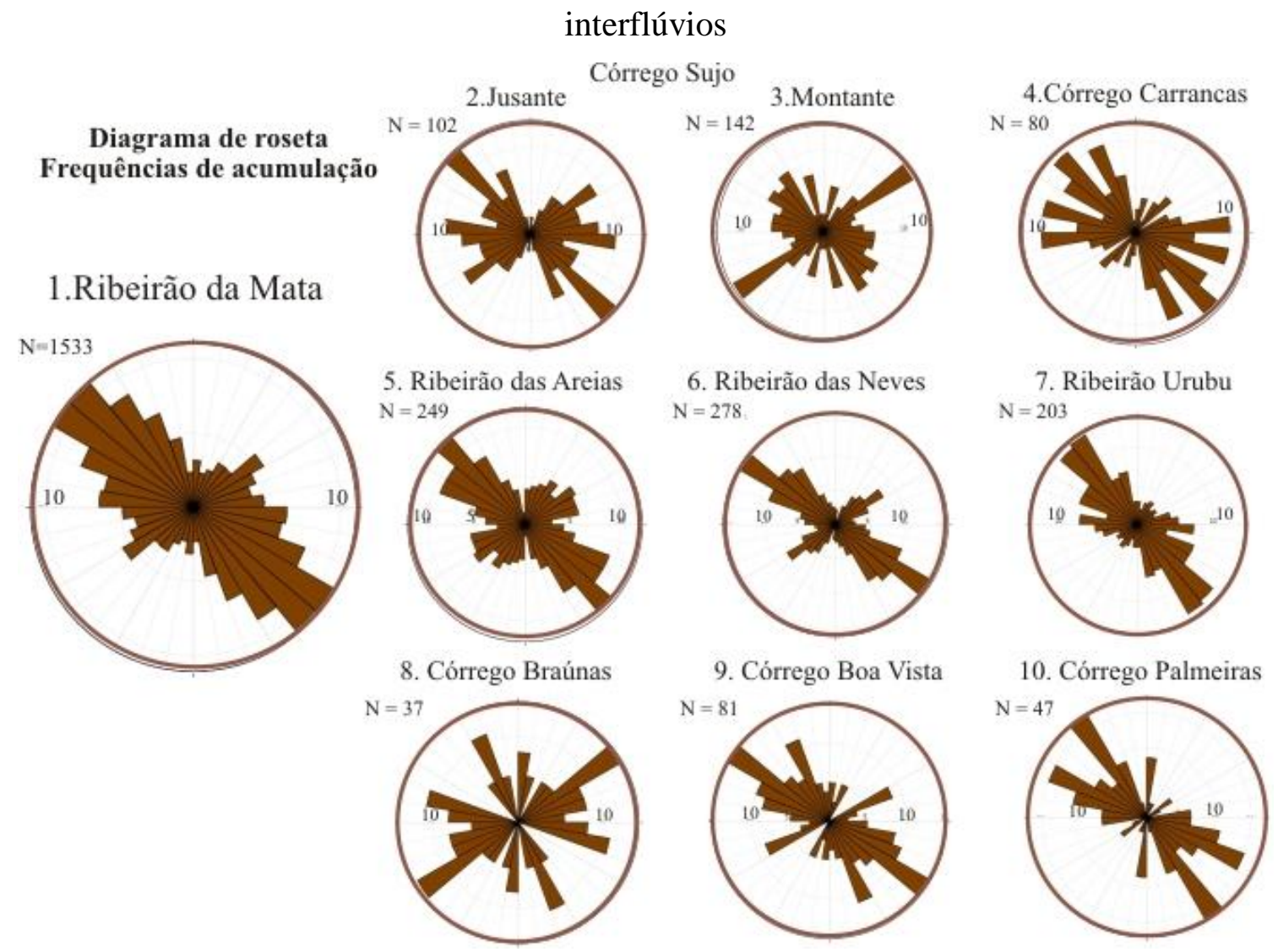

Fonte: Os autores (2018).

Um fator que pode ter motivado essa organização perpendicular desses afluentes, para além do condicionante estrutural, é a alteração na capacidade de dissecação desses afluentes por meio de alterações no nível de base dessa rede, na qual a organização topográfica superficial pode ter influenciado o gradiente de caimento geral topográfico para $\mathrm{NE}$, tal como é identificado pela seção topográfica regional no trecho B-C. Nesse aspecto a rede hidrográfica que drena para o ribeirão da Mata em sua margem direita teve suas cabeceiras voltadas para SW, sendo sua incisão vertical condicionada secundariamente por estruturas herdadas no arcabouço geológico. Essa diferenciação entre um complexo cristalino e um sistema cárstico modelado sobre rochas carbonáticas resulta, também, da maneira como se organiza a rede hidrográfica e sua amplitude de dissecação.

O Índice de Concentração de Rugosidade e a densidade da rede hidrográfica corroboram ao apresentar as maiores rugosidades e densidade de cursos fluviais sobre o embasamento cristalino, visto que essas rochas possuem menor porosidade e são mais dificilmente alteradas mediante o contato hídrico quando comparado aos carbonatos. 
Conforme demonstrado na Figura 4, a superfície topográfica apresenta maior rugosidade na margem direita do ribeirão da Mata sobre o complexo cristalino, cuja bacia do ribeirão das Neves possui morfologia relativamente mais dissecada.

Em contrapartida, nas zonas de cabeceira do ribeirão da Mata, sua extensão ao longo da margem esquerda, bem como suas sub-bacias à jusante correspondendo aos córregos Sujo e Carrancas, são as zonalidades que apresentam menor rugosidade topográfica. Essa organização topográfica regional da bacia do ribeirão da Mata sugere que o modelado do relevo expressa um componente morfoestrutural em sua arquitetura superficial.

Tanto a composição gnáissico-granítica do complexo cristalino possui variabilidade em sua mineralogia, quanto também possui diferentes descontinuidades herdadas. Esse é um fator que pode condicionar a maneira como a rede hidrográfica disseca a superfície em vista a heterogeneidade desse complexo cristalino. A margem esquerda do ribeirão da Mata, por sua vez, possui relativa regularidade topográfica em vista de uma rede hidrográfica atrelada a uma dinâmica subterrânea, cuja superfície pode resguardar testemunhos de momentos anteriores a partir de suas coberturas superficiais inconsolidadas.

Mediante comparativo entre a margem esquerda e direita do ribeirão da Mata, a primeira coincide regionalmente como o trecho de menor rugosidade superficial, bem como a menor densidade de redes de afluentes, o que pode estar diretamente relacionado a uma organização edificada pelo sistema cárstico de Lagoa Santa. A margem direita, por sua vez, apresenta regionalmente tanto maior rugosidade quanto maior densidade hidrográfica na superfície; todavia, há variabilidade em relação aos valores mais elevados.

A sub-bacia do ribeirão das Neves é aquela que apresenta rugosidade superficial mais elevada, ao passo que a sub-bacia do ribeirão das Areias revela maior densidade de afluentes. A cabeceira do ribeirão da Mata correspondente à sub-bacia do córrego Boa Vista, a qual representa uma área de alta densidade hidrográfica, assim como a porção jusante da sub-bacia do ribeirão do Urubu e as cabeceiras da sub-bacia do ribeirão das Neves.

A densidade hidrográfica, por sua vez, nem sempre é coincidente com as maiores rugosidades. A sub-bacia do córrego Sujo apresenta relativa expressão areal na qual se distingue claramente a transição entre o complexo cristalino e as sequências sedimentares, sendo que a densidade hidrográfica foi a principal variável que expressa mais marcante variabilidade. Para essa sub-bacia, seu trecho de jusante está diretamente sobre os carbonatos e releva muito baixa concentração, enquanto sua cabeceira drenada sobre o complexo cristalino possui alta densidade de afluentes. 
Figura 4 - Bacia do ribeirão da Mata: densidade espacial da rugosidade e rede hidrográfica na superfície
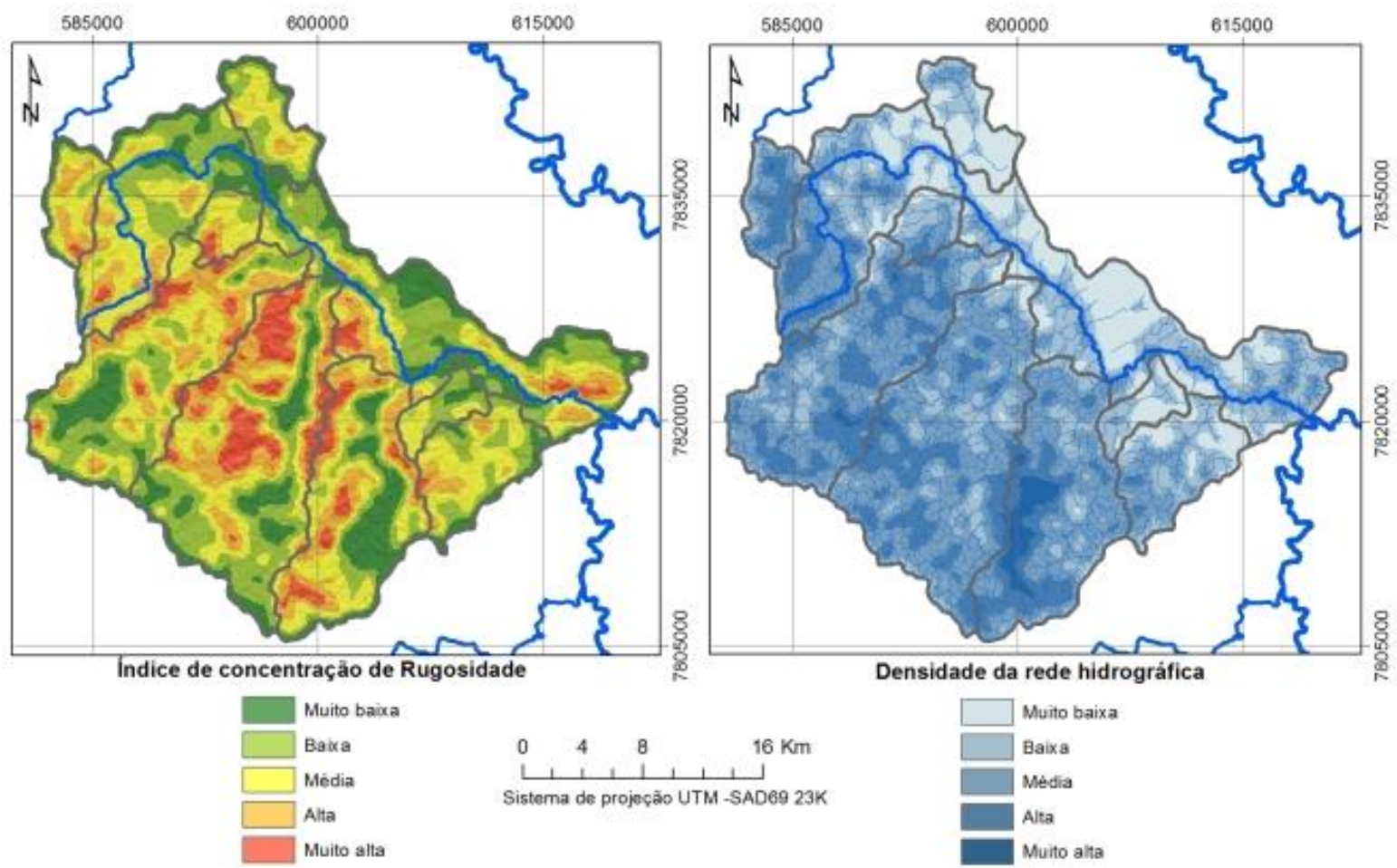

Fonte: Os autores (2018).

\section{CONSIDERAÇÕES FINAIS}

Este trabalho evidenciou que a diversificada litoestrutura presente na transição entre distintas unidades geotectônicas exerceu, na área aqui investigada, papel condicionante fundamental no modelado de seu relevo. Na bacia do ribeirão da Mata, localizada no contato entre embasamento arqueano e bacia sedimentar neoproterozoica, a organização da rede hidrográfica e o modelado do relevo forneceram indicadores quanto ao modo como a superfície foi dissecada por fenômenos e processos comandados pelo rebaixamento do nível de base regional. Valadão e Dominguez (1999) atribuem esse rebaixamento a um evento pliocênico, em decorrência de soerguimento continental que, na região ao norte de Belo Horizonte, onde se insere a área de estudo, teria alcançado magnitude aproximada de $200 \mathrm{~m}$.

Dada estruturação regional da bacia pode envolver, sobretudo, flutuabilidades nos níveis de base que condicionaram a estruturação do atual perímetro da bacia e de sua rede de tributários, além de possíveis componentes tectônicos responsáveis pelo um caimento geral da superfície topográfica para NE. Essa flutuabilidade se revela também como condicionante 
inerente à instalação de knickpoints localizados ao norte de Belo Horizonte, tal como demonstrado por Henriques e Valadão (2016a, b).

Do ponto de vista das técnicas, a orientação geral de talvegues e interflúvios representados em digramas de roseta se revelou recurso importante ao permitir a visualização geral dos principais direcionamentos estruturais da superfície. Para a bacia do ribeirão da Mata, apresenta predomínio NW-SE e secundariamente SW-NE. Essas duas orientações principais, ao que tudo indica, decorrem da direção geral de lineamentos do arcabouço geológico, uma vez que a rede hidrográfica se encontra organizada segundo duas orientações predominantes (NW-SW e SW-NE). A hidrografia também recorta perpendicularmente tal orientação geral NW-SE, o que sugere decorrer da flutuabilidade dos níveis de base associada ou não a possíveis mobilidades crustais.

\section{REFERÊNCIAS}

FILHO, C. O. A.; FONSECA, L. M. G. Lineamentos estruturais a partir de imagem Landsat TM e dados SRTM. In: SIMPÓSIO BRASILEIRO DE SENSORIAMENTO REMOTO, 14., 2009, Natal/RN. Anais... Natal/RN: INPE, 2009. p.3151-3158.

FUNDAÇÃO CENTRO TECNOLÓGICO DE MINAS GERAIS - CETEC; COMISSÃO DE POLÍTICA AMBIENTAL - COPAM. Projeto Diagnóstico Ambiental - Mapa 2 Geomorfologia. Escala 1:1.000.000. 1982.

HASUI, Y. Quadro geral da evolução pré-ordoviciana: a conexão Brasil-África. In: HASUI, Y.; CARNEIRO, C. D. R.; ALMEIDA, F. F. M. de; BARTORELLI, A. (Orgs.) Geologia do Brasil. São Paulo: Editora Beca, Cap. 8, 2012. p.123-130.

HENRIQUES, R. J.; VALADÃO, R. C. Fatores que possam condicionar a geometria de perfis longitudinais de afluentes dos rios das Velhas e Paraopeba em Minas Gerais, Brasil. In: Simpósio Nacional de Geomorfologia, 11., 2016a, Maringá/PR. Anais... Maringá/PR: UGB, 2016a. v.1. p.1- 9. Disponível em: < http://www.sinageo.org.br/2016/trabalhos/3/3-2241121.html>. Acesso em: 27 jun. 2017.

HENRIQUES, R. J.; VALADÃO, R. C. Contribuições do modelo de regressão não-linear logarítmico aplicado à análise de perfis longitudinais em Geomorfologia Fluvial. Revista Geografias, v.1, p.54-70, 2016b. Disponível em: <http://www.igc.ufmg.br/portaldeperiodicos/index.php/geografias/article/view/810/602>. 
Acesso em: 07 jun. 2018.

INSTITUTO BRASILEIRO DE GEOGRAFIA E ESTATÍSTICA - IBGE. Projeto Geominas, cartas topográficas. Escala 1:50.000, 2008.

KING, L. C. Geomorfologia do Brasil Oriental. Revista Brasileira de Geografia, v.18, n.2, p.147-265, $1956 . \quad$ Disponível em: <https://biblioteca.ibge.gov.br/visualizacao/periodicos/115/rbg_1956_v18_n2.pdf>. Acesso em: 07 jun. 2018.

MAGALHÃES JR, A.; SAADI, A. Ritmos da dinâmica fluvial neo-cenozóica controlados por soerguimento regional e falhamento: o vale do rio das Velhas na região de Belo Horizonte, Minas Gerais, Brasil. Revista Geonomos, v.2, n.1, p.42-54, 1994. Disponível em: <http://www.igc.ufmg.br/portaldeperiodicos/index.php/geonomos/article/view/231/210>. Acesso em: 27 set. 2011.

NOCE, C. M.; TEIXEIRA, W.; MACHADO, N. Geoquímica dos gnaisses TTGs e granitoides neoarqueanos do Complexo Belo Horizonte, Quadrilátero Ferrífero, Minas Gerais. Revista Brasileira de Geociências, v.27, n.1, p.25-32, 1997. Disponível em: <http://ppegeo.igc.usp.br/index.php/rbg/article/view/11264>. Acesso em: 07 jun. 2018. PESSOA, P. F. P. Hidrogeologia dos aquíferos cársticos cobertos de Lagoa Santa, MG. 2005. 575f. Tese (Doutorado) - Escola de Engenharia, Universidade Federal de Minas Gerais, Belo Horizonte, 2005.

PILÓ, L. B. Morfologia cárstica e materiais constituintes: dinâmica e evolução da Depressão Poligonal Macacos-Baú - Carste de Lagoa Santa, MG. 1998. 283f. Tese (Doutorado) - Departamento de Geografia, Universidade de São Paulo, São Paulo, 1998.

QUEIROZ, G. L.; SALAMUNI, E.; NASCIMENTO, E. R. Azimuthfinder: ferramenta para a extração de dados e apoio na análise estrutural. Geol.USP, Sér.cient. v.14, n.1, p.69-80, 2014. Disponível em: <https://www.revistas.usp.br/guspsc/article/view/78925>. Acesso em: 05 fev. 2015 .

SAMPAIO, T. V. M.; AUGUSTIN, C. H. R. R. Índice de Concentração da Rugosidade: uma nova proposta metodológica para o mapeamento e quantificação da dissecação do relevo como subsídio a cartografia geomorfológica. Revista Brasileira de Geomorfologia, v.15, n.1, p.47-60, 2014. Disponível em: <http://www.lsie.unb.br/rbg/index.php/rbg/article/view/376>. Acesso em: 05 fev. 2015. STRAHLER, A. N. Quantitative Analysis of Watershed Geomorphology. Transactions, American Geophysical Union, v.38, n.6, p.913-920, 1957. 
VALADÃO, R. C. Evolução de longo-termo do relevo do Brasil oriental (desnudação, superfícies de aplanamento e soerguimentos crustais). 1998, 243f. Tese (Doutorado) Instituto de Geociências, Universidade Federal da Bahia, Salvador, 1998.

VALADÃO, R. C. Geodinâmica de superfícies de aplanamento, desnudação continental e neotectônica ativa como condicionantes da megageomorfologia do Brasil Oriental. Revista Brasileira de Geomorfologia, v.10, n.2, p.77-90, 2009. Disponível em: <http://www.lsie.unb.br/rbg/index.php/rbg/article/view/132>. Acesso em: 27 set. 2011.

VALADÃO, R. C.; DOMINGUEZ, J. M. L. Deformação Tectônica Neocenozóica no Brasil Oriental: zonalidade e magnitude. In: Congresso da Associação Brasileira de Estudos do Quaternário - ABEQUA, 7., 1999, Porto Seguro. Anais... Salvador: CPGG/UFBA, 1999. 